\title{
Up-regulation of LncRNA MEG3 inhibits cell migration and invasion and enhances cisplatin chemosensitivity in bladder cancer cells
}

\author{
S. Q. FENG, X. Y. ZHANG, H. T. FAN, Q. J. SUN, M. ZHANG* \\ Department of Urology, The Second Hospital of Jilin University, Changchun, China \\ ${ }^{*}$ Correspondence: mzhang3830@163.com
}

Received January 25, 2018 / Accepted May 2, 2018

\begin{abstract}
It has been proven that maternally expressed 3 (MEG3), a long non-coding RNA (LncRNA), is down-regulated and inversely correlated with prognosis in various types of cancer, including bladder cancer (BC). Nevertheless, the role of MEG3 in BC has not been fully identified. Herein, we found that MEG3 expression was reduced in 21 BC tumor tissue samples compared to corresponding adjacent tissues. We then established T24 and 5637 cells with a stably integrated expression of MEG3 by G418 resistance screening, and data revealed that the BC cells over-expressing MEG3 displayed weaker migration and invasion ability than control cells. The expression and activity of matrix metalloproteinase (MMP) 2 and MMP9 were down-regulated when MEG3 was over-expressed. Moreover, MEG3 over-expression sensitized BC cells to the chemotherapy drug cisplatin (DDP). DDP treatment significantly induced cell apoptosis, down-regulated bcl2 expression, and up-regulated cleaved-caspase-3 and bax expression in BC cells with MEG3 over-expression. MEG3 and p53 can also stimulate mutual expression in BC cells, thus indicating a potential positive feedback loop of MEG3 and p53. Our combined results suggest that over-expression of MEG3 inhibits migration and invasion and enhances DDP chemo-sensitivity in bladder cancer cells.
\end{abstract}

Key words: LncRNA MEG3, bladder cancer, cisplatin, chemosensitivity, p53

Bladder cancer (BC), one of the most common malignancies worldwide, has a higher incidence in males than females $[1,2]$. The etiology of $\mathrm{BC}$ is quite complicated, involving both genetic and environmental factors [3]. A well-known risk factor is smoking, which causes $31 \%$ and $14 \%$ of BC-related deaths in males and females worldwide [4]. The prognosis of patients with this cancer is still poor, although vast improvement in diagnosis and treatment has been achieved [5]. Therefore, it is essential to develop new therapeutic targets and strategies in the treatment of $\mathrm{BC}$.

The human genome project (HGP) has historically revealed the whole human genome sequences, $98.5 \%$ of which do not encode any protein but have association with multiple diseases $[6,7]$. The $H$. sapiens maternally expressed gene 3 (MEG3) is located on chromosome 14q32.3 that belongs to the imprinted DLK1-MEG3 and encodes a non-coding RNA [8]. Several earlier studies have shown that MEG3 is expressed at low levels in cancer tissues, and is associated with poor prognosis in a variety of cancers, such as gastric cancer [9], tongue squamous cell carcinoma [10], breast cancer [11], cervical cancer [12], osteosarcoma [13] and non-small cell lung cancer [14]. Its expression can significantly inhibit cell proliferation and promote cell apoptosis in some carcinoma cells [15-18]. Interestingly, MEG3 was found to be downregulated in tumor tissues derived from $\mathrm{BC}$ patients, and this low expression correlates with low relapse-free survival [19]. However, its role in regulating the development and progress of $\mathrm{BC}$ remains poorly understood.

In the present study, the expression of MEG3 was first determined in the tumor and adjacent non-tumor tissues from BC patients. Two BC cell lines (T24 and 5637 cells) with a stably integrated expression of MEG3 were established to evaluate how MEG3 over-expression affected the cell migration and invasion and the cisplatin (DDP) chemo-sensitivity of $\mathrm{BC}$ cells in vitro.

\section{Patients and methods}

Patients and tissue samples. A total of 21 pairs of tumor and adjacent non-tumor tissue samples were obtained from patients with primary BC. No patients received chemotherapy or radiotherapy prior to the surgery and all signed the informed consent forms. The study was approved by the Ethical Committee of Jilin University. 
Cells and cell culture. Two BC cell lines, T24 and 5637, were purchased from CHI Scientific, Inc (Maynard, MA, USA). They were cultured in RPMI-1640 medium (Gibco, Grand Island, NY, USA) supplemented with $10 \%$ fetal bovine serum (Hyclone, Logan, UT, USA) and placed in a $37^{\circ} \mathrm{C}$ incubator with $5 \% \mathrm{CO}_{2}$

Real-time PCR. Total RNAs were isolated from cells with a high purity total RNA extraction kit (BioTeke, Beijing, China) and subjected to synthesis of cDNA using Super M-MLV Reverse Transcriptase (BioTeke). Afterwards, the levels of MEG3 and GAPDH were detected by real-time PCR using the primers as follows: MEG3 forward, TCAGGCAGGATCTGGCATAGAGG, reverse, GAGCGAGTCAGGAAGCAGTGGGT; GAPDH forward, GAAGGTCGGAGTCAACGGAT, reverse, CCTGGAAGATGGTGATGGGAT. The relative expression of MEG3 was calculated by the $2^{-\Delta \Delta \mathrm{CT}}$ method.

Generation of stable cell lines and transient transfection. The full-length lncRNA MEG3 cDNA was cloned into the Xho1 and EcoR1 sites of the pEGFP-N1 vector (Sangon, Shanghai, China), and the empty pEGFP-N1 vector was used as control. The plasmids were transfected into T24 and 5637 cells using Lipofectamine 2000 (Invitrogen, Carlsbad, CA, USA). The stably transfected cells were then selected with G418 (Invitrogen). The plasmid expressing p53 was purchased from SinoBiological Inc. (Beijing, China) and was transiently transfected into T24 and 5637 cells using Lipofectamine 2000.

Wound healing assay. The wound healing assay determined cell migration ability. In brief, cells seeded in six-well plates were cultured to confluence, and subsequently the complete medium was replaced with serum-free medium containing $1 \mu \mathrm{g} / \mathrm{ml}$ mitomycin C (Sigma, St. Louis, MO, USA). One hour later, a straight scratch was made on the bottom of each plate with a $200 \mu$ pipette tip. Thereafter, cellular debris was washed away with PBS and the remaining cells were continuously cultured in serum-free medium in an incubator at $37^{\circ} \mathrm{C}$ with $5 \% \mathrm{CO}_{2}$. The cell images were captured at 0,12 and $24 \mathrm{~h}$ using an inverted phase contrast microscope (Motic, Xiamen, China).

Transwell assay. Cell invasion ability was examined by Transwell assay. In brief, the cells were re-suspended at a final density of $1 \times 10^{5}$ cells $/ \mathrm{ml}$. Transwell chambers (Corning, Corning, NY, USA) pre-coated with Matrigel (BD, Franklin Lakes, NJ, USA) were plated into 24 -well plates. Then $200 \mu \mathrm{l}$ of the cell suspension was added into upper chambers, and the lower chambers were filled with $800 \mu \mathrm{l}$ culture medium containing $30 \%$ FBS. After incubation for $24 \mathrm{~h}$ at $37^{\circ} \mathrm{C}$, the upper surfaces of the chambers were wiped with a cotton bud to remove the non-invasive cells. The remaining cells were fixed with $4 \%$ paraformaldehyde for 20 minutes at room temperature and stained with $0.5 \%$ crystal violet for 5 minutes. The stained cells were counted in five separate fields under a light microscope (Motic).

Western blot. Total protein was extracted from cells on ice with RIPA buffer (Beyotime Institute of Biotechnology,
Beijing, China) supplemented with protease inhibitor PMSF. Protein concentration was determined with a BCA protein assay kit (Beyotime Institute of Biotechnology). The samples were separated by SDS-polyacrylamide gel electrophoresis (SDS-PAGE) and transferred to polyvinylidene fluoride (PVDF) membranes. The membranes were blocked with 5\% skim milk and incubated with one of the primary antibodies against matrix metalloproteinase (MMP)2 (D198344, 1:500, Sangon Biotech), MMP9 (D261999, 1:500, Sangon Biotech), cleaved-Caspase-3 (ab2302, 1:1000, Abcam), bcl-2 (D160117, 1:500, Sangon Biotech), bax (D120073, 1:500, Sangon Biotech), p53 (KG21083-2, 1:500, KeyGen) and GAPDH (60004-1-Ig, 1:500, Proteintech) overnight at $4^{\circ} \mathrm{C}$. Secondary antibodies were then used to probe the primary antibodies for $45 \mathrm{~min}$ at $37^{\circ} \mathrm{C}$. The bands were visualized by enhanced chemiluminescence (Beyotime Institute of Biotechnology) and analyzed by gel imaging system (Beijing Liuyi Biotechnology Co., Ltd., Beijing, China). The expression levels of target proteins were normalized to the expression levels of GAPDH.

Gelatin zymography. The activity of MMP2 and MMP9 was determined with Gelatin zymography. Briefly, the samples were subjected to electrophoresis on 10\% SDS-PAGE containing $1 \mathrm{mg} / \mathrm{ml}$ gelatin (sigma). Afterwards, the gel was eluted in elution buffer (2.5\% Triton X-100, $50 \mathrm{mM}$ Tris- $\mathrm{HCl}$, $5 \mathrm{mM} \mathrm{CaCl}, 1 \mu \mathrm{M} \mathrm{ZnCl}, \mathrm{pH} 7.6)$ for $40 \mathrm{~min}$ twice, rinsed with wash solution $\left(50 \mathrm{mM}\right.$ Tris- $\mathrm{HCl}, 5 \mathrm{mM} \mathrm{CaCl}_{2}, 1 \mu \mathrm{M}$ $\left.\mathrm{ZnCl}_{2}, \mathrm{pH} 7.6\right)$ for 20 min twice, and incubated with incubation buffer $(50 \mathrm{mM}$ Tris- $\mathrm{HCl}, 5 \mathrm{mM} \mathrm{CaCl}, 1 \mu \mathrm{M} \mathrm{ZnCl}$, $0.02 \%$ Brij, $0.2 \mathrm{M} \mathrm{NaCl}$ ). Then $0.05 \%$ Coomassie brilliant blue G-250 was used for staining. After de-coloration, the bands were captured and analyzed by gel imaging system (Beijing Liuyi Biotechnology Co., Ltd.).

Methylthiazoletetrazolium (MTT) assay. Cell proliferation was evaluated by MTT assay. In brief, cells were seeded in 96-well plates at a density of $4 \times 10^{3}$ cells/well. After cell attachment, the cells were treated with a series of concentrations of DDP, which were as follows: for T24 cells (Parental, Vector and MEG3), 0, 10, 15, 20, 25 and $30 \mathrm{mg} / \mathrm{l}$ for 5637 cells (Parental, Vector and MEG3): 0, 1, 2, 4, 6 and $8 \mathrm{mg} / \mathrm{l}$. After the 24-h incubation, the medium was replaced with fresh medium containing $0.5 \mathrm{mg} / \mathrm{ml}$ MTT. Four hours later, the supernatant was discarded and $150 \mu \mathrm{l}$ of dimethyl sulfoxide (DMSO) was added to each well in the dark. Ten minutes later, the absorbance value was measured at $570 \mathrm{~nm}$ by Microplate Reader (BioTek, Winooski, VT, USA). The halfmaximum inhibitory concentration (IC50) of DDP in each group was calculated.

Flow cytometry. Cell apoptosis was evaluated by annexin $\mathrm{V} /$ propidium iodide binding assay. Briefly, cells were placed in 6-well dishes, grew to a confluent $90 \%$ and were then treated with DDP for $24 \mathrm{~h}$. The cells were collected, washed, and re-suspended in $500 \mu \mathrm{l}$ binding buffer. Thereafter, cells were incubated with $5 \mu \mathrm{l}$ AnnexinV-Light 650 and $10 \mu \mathrm{l}$ propidium iodide in the dark at room temperature for 
$15 \mathrm{~min}$. The percentage of apoptosis cells was detected by flow cytometry (BD).

Statistical analysis. The results were presented as the mean \pm SD (standard deviation). The significance of difference was evaluated by student's t-test or two-way analysis of variance (ANOVA) with the GraphPad Prism version 7.00 analysis software (San Diego, CA, USA). P-value less than 0.05 is statistically significant. ${ }^{*} \mathrm{p}<0.05,{ }^{* *} \mathrm{p}<0.01$, and ${ }^{* * *} \mathrm{p}<0.001$.

\section{Results}

Forced over-expression of MEG3 in BC cells. We detected the expression of MEG3 in 21 paired tumor and non-tumor samples from patients with BC using real-time PCR. Figure 1A shows that the expression of MEG3 was lower in tumor tissues than that in corresponding normal tissues. To investigate the role of MEG3 in the development and progress of BC, we established two stable cell lines (T24 and 5637) with MEG3 over-expression. The expression of MEG3 in those two cell lines was detected by real-time PCR. As shown in Figure 1B, the expression of MEG3 was significantly up-regulated in cells transfected with MEG3 overexpression vectors.
Effects of MEG3 over-expression on BC cell migration and invasion. Wound healing assay determined cell migration ability. As shown in Figure 2A, the migration ability of T24 and 5637 cells was evidently inhibited when MEG3 was over-expressed. Results from the transwell assay revealed significant reduction in cell invasion following MEG3 overexpression (Figure 2B). Moreover, data from western blot assay indicated that the expression levels of MMP2 and MMP9 were markedly decreased in T24 and 5637 cells overexpressing MEG3 (Figure 2C). Their activities were also suppressed by MEG3 over-expression (Figure 2D).

MEG3 over-expression sensitized BC cells to the DDP chemotherapy drug. We then measured the chemo-sensitivity of the control $\mathrm{BC}$ cells and those over-expressing MEG3 to DDP. As shown in Figure 3A, DDP dose-dependently inhibited proliferation of T24 and 5637 cells, and this anti-proliferation effect in MEG3-elevated cells was greater than in controls. The IC50 value in BC cells over-expressing MEG3 was lower than in control cells (Figure 3B). In addition, results from flow cytometry assay demonstrated that MEG3 over-expression enhanced the chemo-sensitivity of BC cells to DDP treatment (Figure 3C). Moreover, results of western blot analysis revealed that DDP treatment further up-regulated the protein levels of cleaved caspase- 3 and

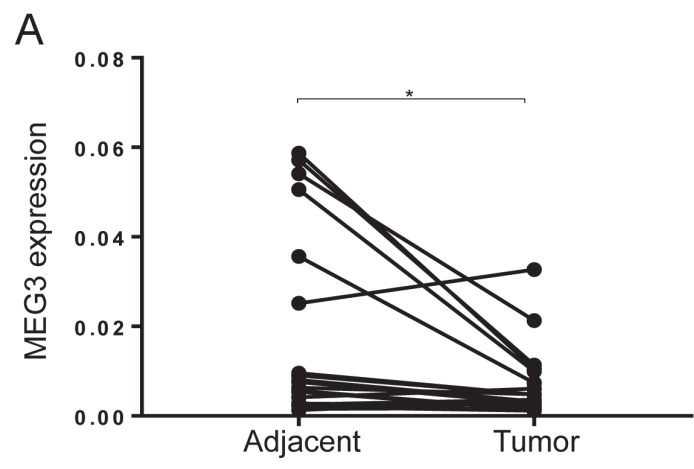

B

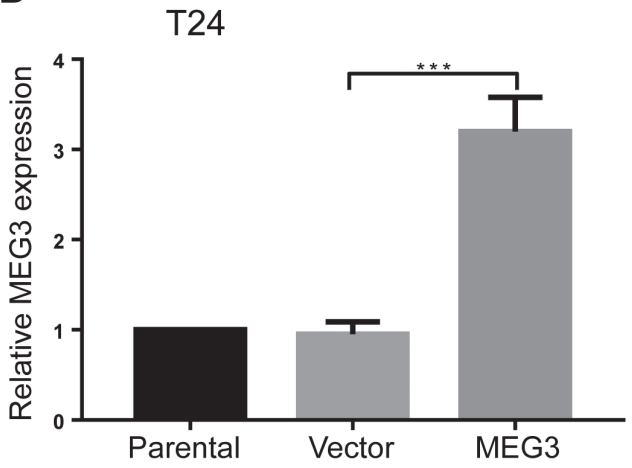

5637

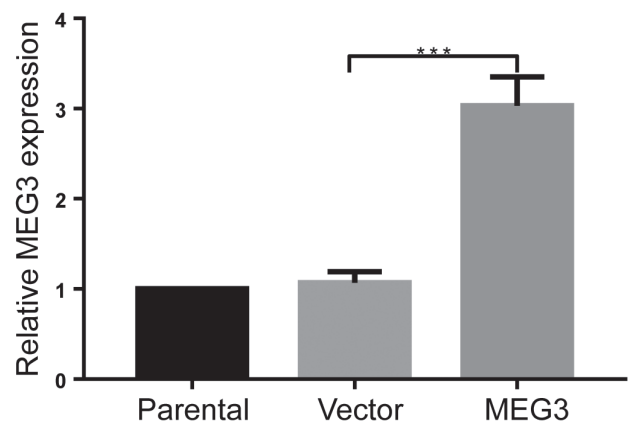

Figure 1. Up-regulation of MEG3 in BC cells. A) Real-time PCR was performed for the detection of MEG3 in BC tissues and adjacent tissues. (B) The over-expression efficiency of MEG3 was verified by real-time PCR. Data is presented as the mean $\pm \mathrm{SD},{ }^{*} \mathrm{p}<0.05 ;{ }^{* * *} \mathrm{p}<0.001$. 
A
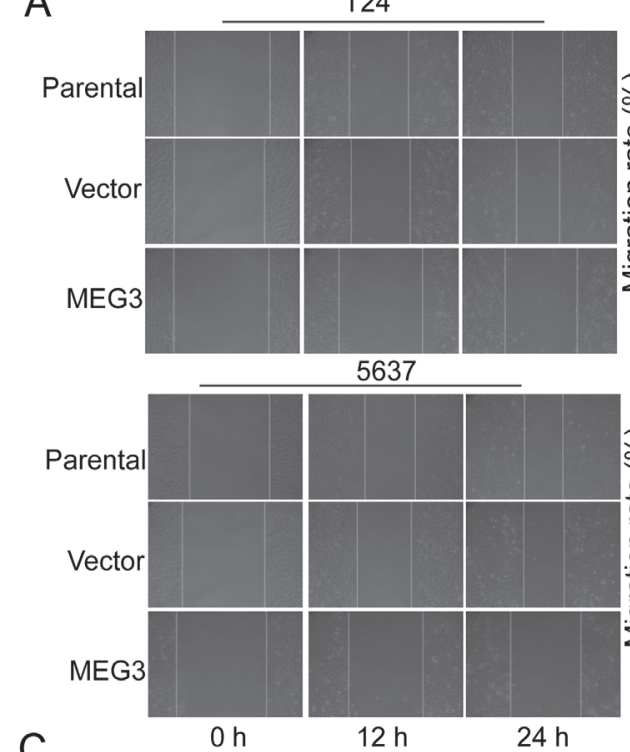

C
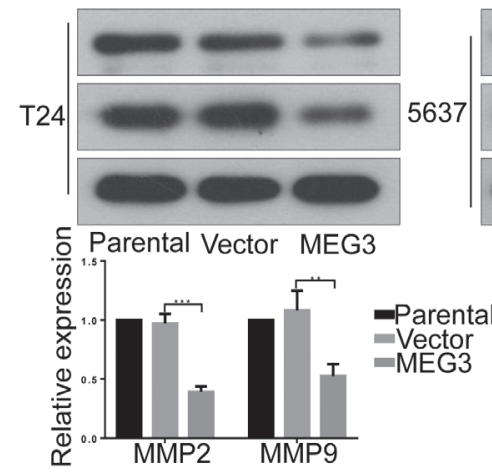
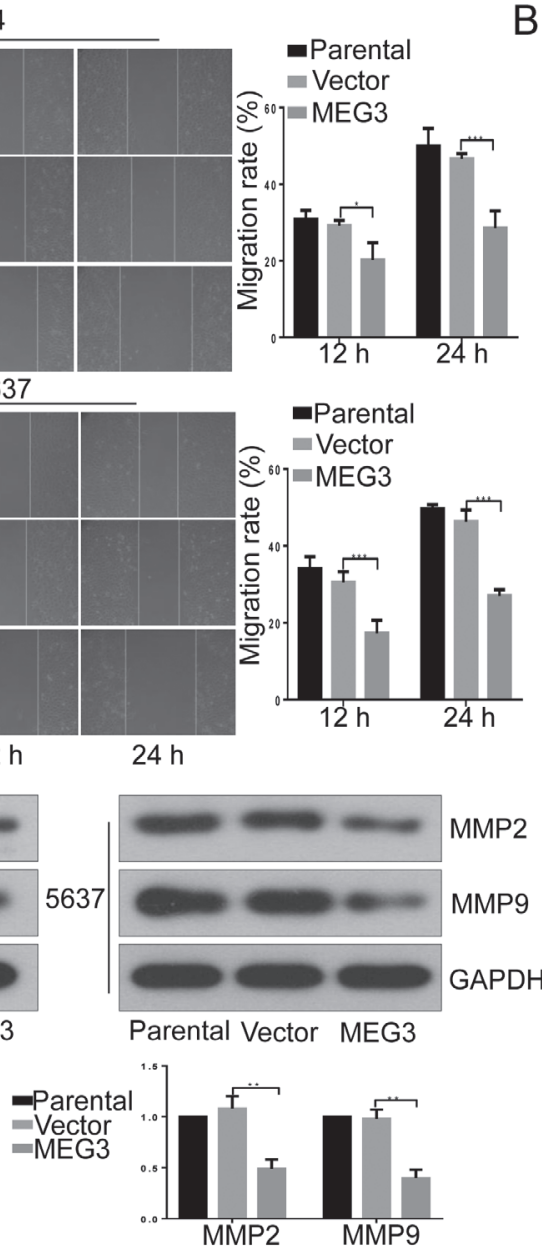

B

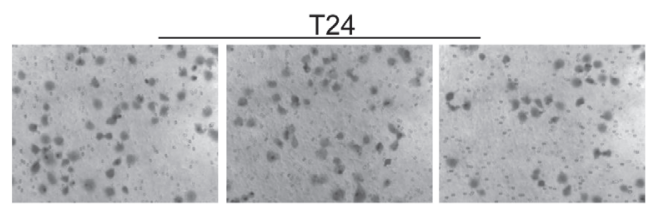

5637
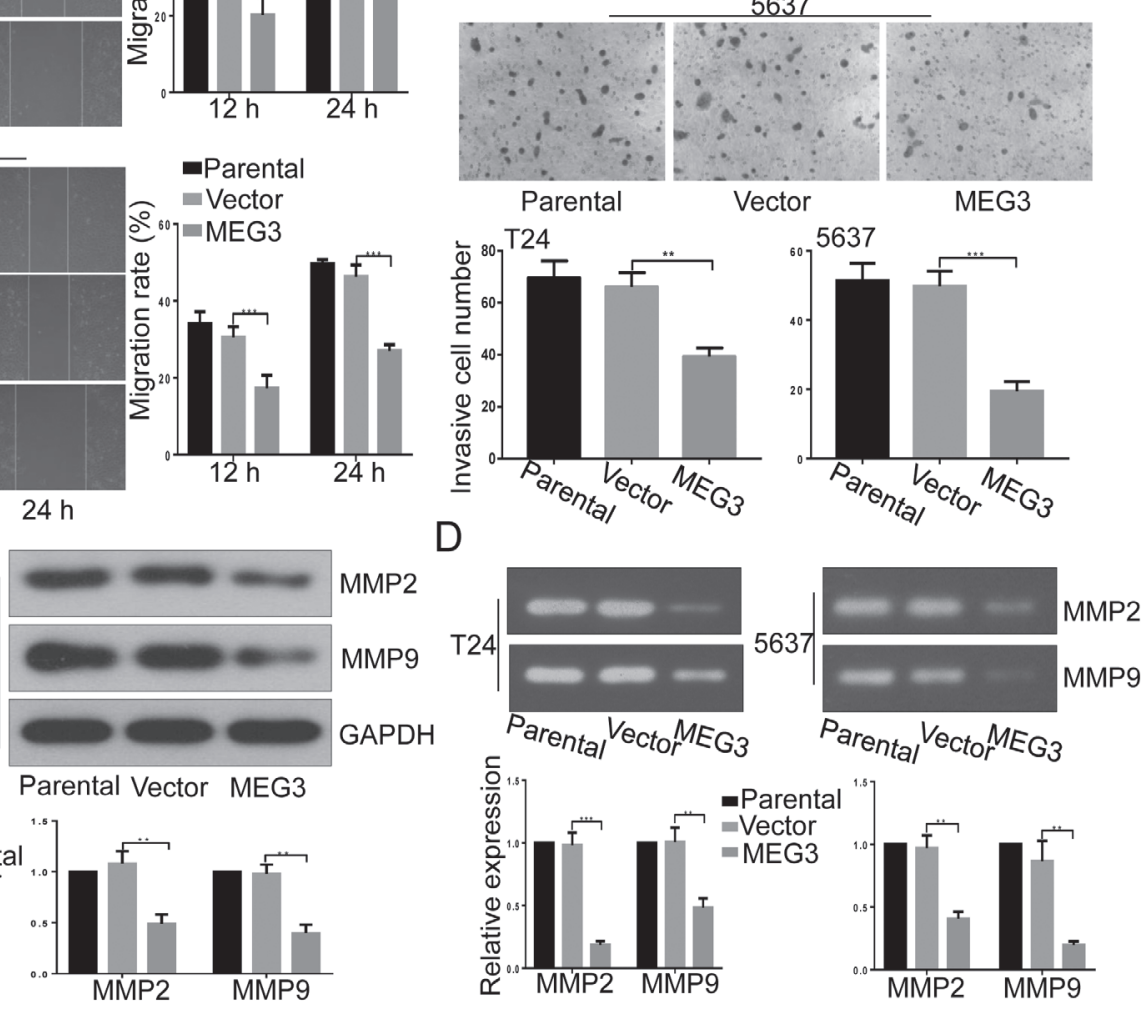

Figure 2. The ability of migration and invasion was significantly weakened in MEG3-elevated BC cells. A) cellular migration ability was determined by wound healing assay. B) Transwell assay was used to measure cell invasion ability. C) The expression levels of MMP2 and MMP9 were evaluated by western blotting. D) The activity of MMP2 and MMP9 was assessed by gelatin zymography. Data is presented as the mean \pm SD, ${ }^{\star} \mathrm{p}<0.05 ;{ }^{\star *} \mathrm{p}<0.01$; ${ }^{* * *} \mathbf{p}<0.001$.

bax, and down-regulated bcl2 expression in MEG3-overexpressed BC cells (Figure 3D).

Effect of MEG3 over-expression on p53 expression in BC cells. Finally, we evaluated the expression level of p53, a potential key regulator in mediating cell growth and chemosensitivity in BC cells. Western blot analysis demonstrated that forced over-expression of MEG3 significantly promoted p53 expression in T24 and 5637 cells (Figure 4A). In turn, the p53 over-expression increased MEG3 expression in BC cells (Figure 4B). These results suggest that MEG3 and p53 can mutually stimulate the expression in $\mathrm{BC}$ cells.

\section{Discussion}

LncRNAs were identified in the early 1990's and are defined as a class of non-coding RNAs which contain $>200$ nucleotides and lack significant open reading frame [20]. The role of
LncRNAs has been extensively researched in a variety of pathophysiological processes, including autism spectrum disorders [21], cancers [22], cardiovascular disease [23], Alzheimer's disease [24] and in reproduction and development [25]. Because prior findings revealed low expression of MEG3 in BC tissues [19], we conducted in vitro experiments using T24 and 5637 cells to investigate the role of MEG3 in the metastasis and chemotherapy sensitivity of $\mathrm{BC}$ cells. We found that up-regulation of MEG3 suppressed migration and invasion and enhanced BC cell chemo-sensitivity to DDP in vitro.

MMPs are a family of zinc dependent endopeptidases involved in extracellular matrix (ECM) degradation. MMP2 and MMP9 are the two major MMPs and their over-expression has been proven to promote metastasis of many malignant tumors, including $\mathrm{BC}[26,27]$. We found that both the expression and activity of MMP2 and MMP9 were inhibited following forced up-regulation of MEG3. Moreover, it has 
A

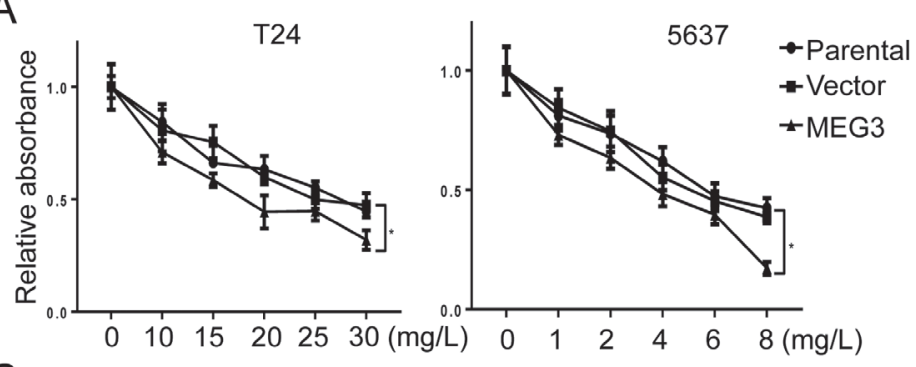

B

\begin{tabular}{|c|c|c|c|c|}
\hline \multirow{2}{*}{ Cells } & \multicolumn{3}{|c|}{ IC50 (mg/L) } & \multirow{2}{*}{-Folds } \\
\hline & DDP & $\mathrm{DP}+\mathrm{vec}$ & $\mathrm{DDP}+\mathrm{MEG} 3$ & \\
\hline $\mathrm{T} 24$ & 27.74 & 27.24 & 18.70 & 1.45 \\
\hline 5637 & 5.95 & 5.34 & 3.02 & 1.77 \\
\hline
\end{tabular}

C
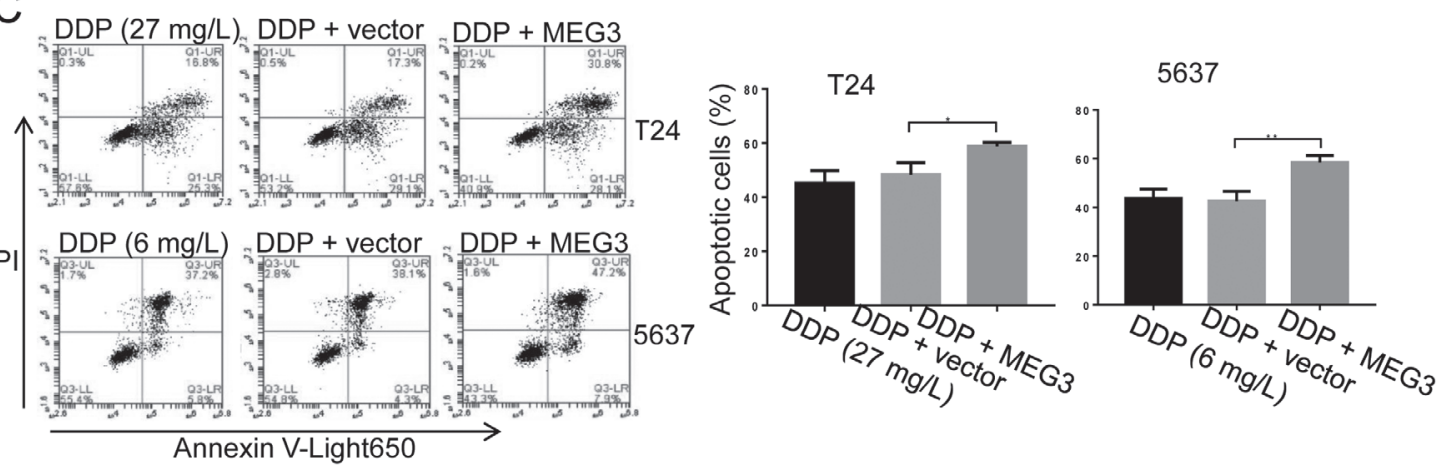

D
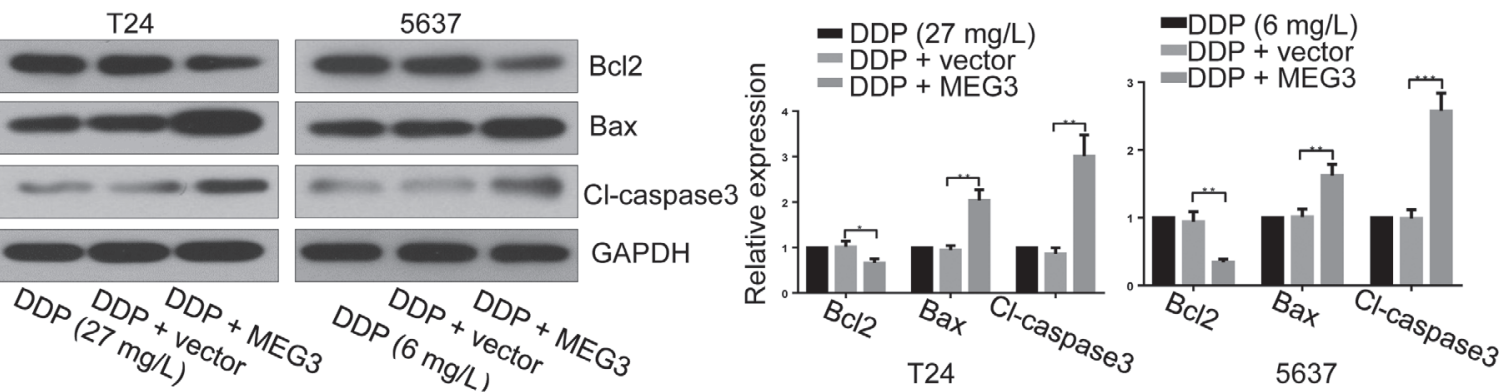

Figure 3. The DDP chemosensitivity was enhanced in MEG3-elevated BC cells. A) Cell proliferation ability was determined by MTT assay. (B) Cell apoptosis was assessed by flow cytometry. C) The expression levels of cleaved-caspase-3, bcl-2 and bax were detected through western blot analysis. Data is presented as the mean $\pm \mathrm{SD},{ }^{\star} \mathrm{p}<0.05 ;{ }^{* *} \mathrm{p}<0.01 ;{ }^{* * *} \mathrm{p}<0.001$.

been reported that MEG3 over-expression can enhance DDP chemo-sensitivity in lung cancer cells [28] and glioma cells [29]. As DDP is also a main chemotherapeutic drug in BC treatment, we investigated whether MEG3 over-expression also augments BC cell sensitivity to DDP. As expected, we found that the anti-proliferative and pro-apoptotic effects of DDP were stronger in BC cells over-expressing MEG3. The alterations in pro-apoptotic cleaved-caspase- 3 and bax, and anti-apoptotic bcl2 induced by DDP were also more significant in BC cells with high MEG3 level.

Previous studies have proven that MEG3 can inhibit cell growth via the p53 pathway in gastric cancer [15], neuroblastoma [30], breast cancer [31], and pancreatic cancer [32], and that its over-expression augments DDP chemosensitivity in lung cancer by modulating the p53 pathway [28]. Ying et al. demonstrated that down-regulated MEG3 can activate autophagy and promote cell proliferation in $\mathrm{BC}$
[33]. However, it was previously unknown if p53 participated in MEG3-mediated chemo-sensitivity in BC cells. Herein, MEG3 and p53 were found to induce the expression of each other in $\mathrm{BC}$ cells, thus suggesting a potential positive feedback loop between MEG3 and p53. In addition to the 553 pathway, other cancer-related signaling pathways are also modulated by MEG3 in a variety of cancers, such as in the $\mathrm{Wnt} / \beta$-catenin [34,35], PI3K/AKT [36] and retinoblastoma protein pathways [37]. MicroRNAs involved in tumor cell proliferation and apoptosis are also reported to be modulated by MEG3 [16,17,38]. Further experiments will be performed to investigate whether other pathways or microRNAs are involved in the anti-survival role of MEG3 in $\mathrm{BC}$ cells.

Our combined results confirm that MEG3 over-expression restrains $\mathrm{BC}$ cell migration and invasion and enhances their DDP chemo-sensitivity. Finally, while p53 up-regulation also 
A

T24
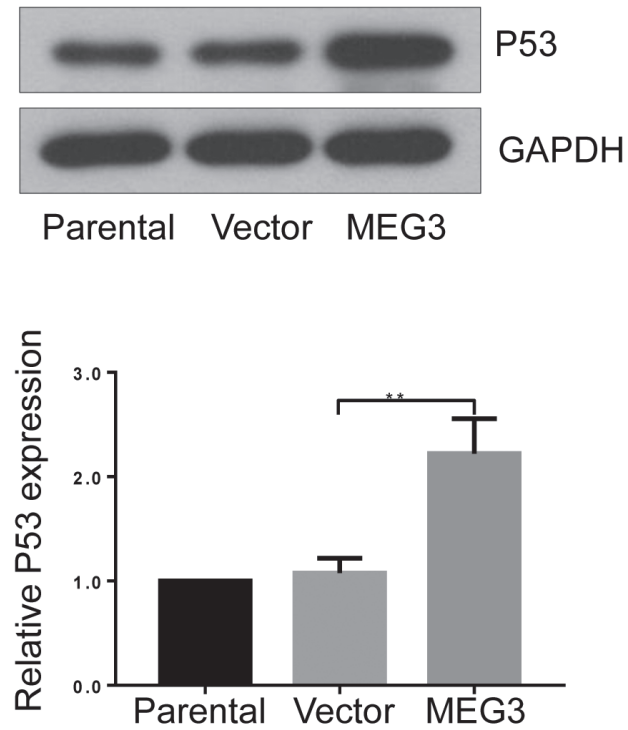

$\mathrm{B}$

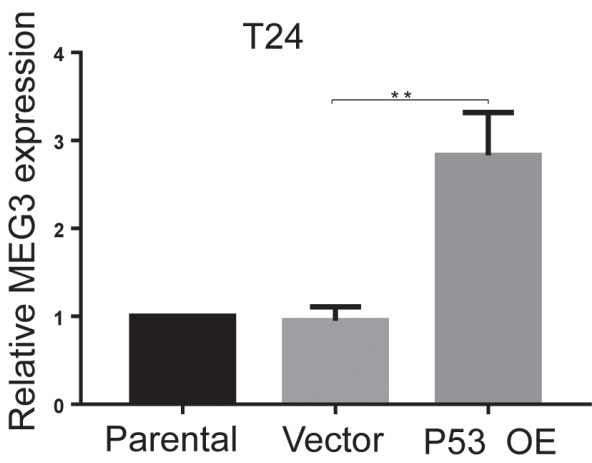

5637
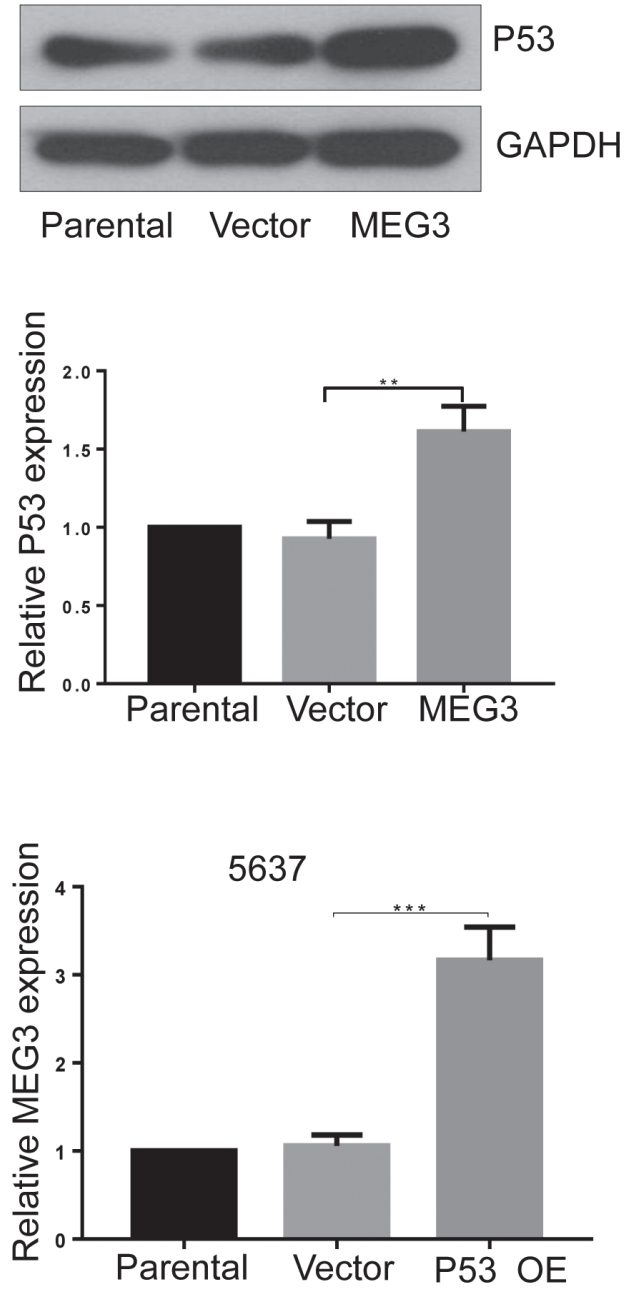

Figure 4. The expression of $\mathrm{p} 53$ was increased in MEG3-elevated BC cells. A) The expression of p53 in MEG3-elevated BC cells was detected by western blotting. B) The expression of MEG3 in p53-elevated BC cells was evaluated by real-time PCR. Data is presented as the mean $\pm S D,{ }^{* *} p<0.01,{ }^{\star * *} p<0.001$.

contributes to MEG3's anti-survival effects, it is suggested that MEG3 can be a successful therapeutic target in bladder cancer treatment.

\section{References}

[1] SIEGEL RL, MILLER KD, JEMAL A. Cancer Statistics, 2017. CA Cancer J Clin 2017; 67: 7-30. https://doi.org/10.3322/ caac. 21387

[2] MILLER KD, SIEGEL RL, LIN CC, MARIOTTO AB, KRAMER JL et al. Cancer treatment and survivorship statistics, 2016. CA Cancer J Clin 2016; 66: 271-289. https://doi. org/10.3322/caac. 21349
[3] WANG S, XUE S, DAI Y, YANG J, CHEN Z et al. Reduced expression of microRNA-100 confers unfavorable prognosis in patients with bladder cancer. Diagn Pathol 2012; 7: 159. https://doi.org/10.1186/1746-1596-7-159

[4] GANJI SM, SAIDIJAM M, AMINI R, MOUSAVI-BAHAR $\mathrm{SH}, \mathrm{SHABAB} \mathrm{N}$ et al. Evaluation of MicroRNA-99a and MicroRNA-205 Expression Levels in Bladder Cancer. Int J Mol Cell Med 2017; 6: 87-95. https://doi.org/10.22088/acadpub. BUMS.6.2.3

[5] HE A, LIU Y, CHEN Z, LI J, CHEN M et al. Over-expression of long noncoding RNA BANCR inhibits malignant phenotypes of human bladder cancer. J Exp Clin Cancer Res 2016; 35: 125. https://doi.org/10.1186/s13046-0160397-9 
[6] HIRSCH N, BIRNBAUM RY. Dual Function of DNA Sequences: Protein-Coding Sequences Function as Transcriptional Enhancers. Perspect Biol Med 2015; 58: 182-195. https://doi.org/10.1353/pbm.2015.0026

[7] CHECK HAYDEN E. Human genome at ten: Life is complicated. Nature 2010; 464: 664-667. https://doi. org/10.1038/464664a

[8] ZHOU Y, ZHANG X, KLIBANSKI A. MEG3 noncoding RNA: a tumor suppressor. J Mol Endocrinol 2012; 48: R4553. https://doi.org/10.1530/JME-12-0008

[9] SUN M, XIA R, JIN F, XU T, LIU Z et al. Downregulated long noncoding RNA MEG3 is associated with poor prognosis and promotes cell proliferation in gastric cancer. Tumor Biol 2014; 35: 1065-1073. https://doi.org/10.1007/s13277013-1142-z

[10] JIA LF, WEI SB, GAN YH, GUO Y, GONG K et al. Expression, regulation and roles of miR-26a and MEG3 in tongue squamous cell carcinoma. Int J Cancer 2014; 135: 2282-2293. https://doi.org/10.1002/ijc.28667

[11] ZHANG JJ, GUO SH, JIA BQ. Down-regulation of long noncoding RNA MEG3 serves as an unfavorable risk factor for survival of patients with breast cancer. Eur Rev Med Pharmacol Sci 2016; 20: 5143-5147.

[12] ZHANG J, LIN Z, GAO Y, YAO T. Downregulation of long noncoding RNA MEG3 is associated with poor prognosis and promoter hypermethylation in cervical cancer. J Exp Clin Cancer Res 2017; 36: 5. https://doi.org/10.1186/s13046016-0472-2

[13] TIAN ZZ, GUO XJ, ZHAO YM, FANG Y. Decreased expression of long non-coding RNA MEG3 acts as a potential predictor biomarker in progression and poor prognosis of osteosarcoma. Int J Clin Exp Pathol 2015; 8: 15138-15142.

[14] ZHANG Z, LIU T, WANG K, QU X, PANG Z et al. Downregulation of long non-coding RNA MEG3 indicates an unfavorable prognosis in non-small cell lung cancer: Evidence from the GEO database. Gene 2017; 630: 49-58. https://doi. org/10.1016/j.gene.2017.08.001

[15] WEI GH, WANG X. lncRNA MEG3 inhibit proliferation and metastasis of gastric cancer via p53 signaling pathway. Eur Rev Med Pharmacol Sci 2017; 21: 3850-3856.

[16] ZHANG W, SHI S, JIANG J, LI X, LU H et al. LncRNA MEG3 inhibits cell epithelial-mesenchymal transition by sponging miR-421 targeting E-cadherin in breast cancer. Biomed Pharmacother 2017; 91: 312-319. https://doi.org/10.1016/j. biopha.2017.04.085

[17] ZHANG J, YAO T, WANG Y, YU J, LIU Y et al. Long noncoding RNA MEG3 is downregulated in cervical cancer and affects cell proliferation and apoptosis by regulating miR-21. Cancer Biol Ther 2016; 17: 104-113. https://doi.org/10.1080/ 15384047.2015.1108496

[18] LU KH, LI W, LIU XH, SUN M, ZHANG ML et al. Long non-coding RNA MEG3 inhibits NSCLC cells proliferation and induces apoptosis by affecting p53 expression. BMC Cancer 2013; 13: 461. https://doi.org/10.1186/1471-2407-13461
[19] DUAN W, DU L, JIANG X, WANG R, YAN S et al. Identification of a serum circulating lncRNA panel for the diagnosis and recurrence prediction of bladder cancer. Oncotarget 2016; 7: 78850-78858. https://doi.org/10.18632/oncotarget. 12880

[20] PETERS T, SCHROEN B. Missing links in cardiology: long non-coding RNAs enter the arena. Pflugers Arch 2014; 466: 1177-1187. https://doi.org/10.1007/s00424-014-1479-1

[21] TANG J, YU Y, YANG W. Long noncoding RNA and its contribution to autism spectrum disorders. CNS Neurosci Ther 2017; 23: 645-656. https://doi.org/10.1111/cns.12710

[22] BHAN A, SOLEIMANI M, MANDAL SS. Long Noncoding RNA and Cancer: A New Paradigm. Cancer Res 2017; 77: 3965-3981. https://doi.org/10.1158/0008-5472.CAN-162634

[23] JIANG X, NING Q. The emerging roles of long noncoding RNAs in common cardiovascular diseases. Hypertens Res 2015; 38: 375-379. https://doi.org/10.1038/hr.2015.26

[24] LUO Q, CHEN Y. Long noncoding RNAs and Alzheimer's disease. Clin Interv Aging 2016; 11: 867-872. https://doi. org/10.2147/CIA.S107037

[25] TAYLOR DH, CHU ET, SPEKTOR R, SOLOWAY PD. Long non-coding RNA regulation of reproduction and development. Mol Reprod Dev 2015; 82: 932-956. https://doi. org/10.1002/mrd.22581

[26] RODRIGUEZ FABA O, PALOU-REDORTA J, FERNANDEZ-GOMEZ JM, ALGABA F, EIRO N et al. Matrix Metalloproteinases and Bladder Cancer: What is New? ISRN Urol 2012; 2012: 581539. https://doi.org/10.5402/2012/581539

[27] KANAYAMA H. Matrix metalloproteinases and bladder cancer. J Med Invest 2001; 48: 31-43.

[28] XIA Y, HE Z, LIU B, WANG P, CHEN Y. Downregulation of Meg3 enhances cisplatin resistance of lung cancer cells through activation of the WNT/beta-catenin signaling pathway. Mol Med Rep 2015; 12: 4530-4537. https://doi. org/10.3892/mmr.2015.3897

[29] MA B, GAO Z, LOU J, ZHANG H, YUAN Z et al. Long noncoding RNA MEG3 contributes to cisplatin induced apoptosis via inhibition of autophagy in human glioma cells. Mol Med Rep 2017; 16: 2946-2952. https://doi.org/10.3892/ mmr.2017.6897

[30] TANG W, DONG K, LI K, DONG R, ZHENG S. MEG3, HCN3 and linc01105 influence the proliferation and apoptosis of neuroblastoma cells via the HIF-1alpha and p53 pathways. Sci Rep 2016; 6: 36268. https://doi.org/10.1038/ srep36268

[31] SUN L, LI Y, YANG B. Downregulated long non-coding RNA MEG3 in breast cancer regulates proliferation, migration and invasion by depending on p53's transcriptional activity. Biochem Biophys Res Commun 2016; 478: 323-329. https://doi.org/10.1016/j.bbrc.2016.05.031

[32] GU L, ZHANG J, SHI M, ZHAN Q, SHEN B et al. IncRNA MEG3 had anti-cancer effects to suppress pancreatic cancer activity. Biomed Pharmacother 2017; 89: 1269-1276. https:// doi.org/10.1016/j.biopha.2017.02.041 
[33] YING L, HUANG Y, CHEN H, WANG Y, XIA L et al. Downregulated MEG3 activates autophagy and increases cell proliferation in bladder cancer. Mol Biosyst 2013; 9: 407-411. https://doi.org/10.1039/c2mb25386k

[34] ZHENG Q, LIN Z, XU J, LU Y, MENG Q et al. Long noncoding RNA MEG3 suppresses liver cancer cells growth through inhibiting beta-catenin by activating PKM2 and inactivating PTEN. Cell Death Dis 2018; 9: 253. https://doi.org/10.1038/ s41419-018-0305-7

[35] LIU Z, WU C, XIE N, WANG P. Long non-coding RNA MEG3 inhibits the proliferation and metastasis of oral squamous cell carcinoma by regulating the WNT/beta-catenin signaling pathway. Oncol Lett 2017; 14: 4053-4058. https:// doi.org/10.3892/ol.2017.6682
[36] ZHANG L, LIANG X, LI Y. Long non-coding RNA MEG3 inhibits cell growth of gliomas by targeting miR-93 and inactivating PI3K/AKT pathway. Oncol Rep 2017; 38: 24082416. https://doi.org/10.3892/or.2017.5871

[37] KRUER TL, DOUGHERTY SM, REYNOLDS L, LONG E, DE SILVA T et al. Expression of the lncRNA Maternally Expressed Gene 3 (MEG3) Contributes to the Control of Lung Cancer Cell Proliferation by the Rb Pathway. PLoS One 2016; 11: e0166363. https://doi.org/10.1371/journal.pone.0166363

[38] QIN N, TONG GF, SUN LW, XU XL. Long Noncoding RNA MEG3 Suppresses Glioma Cell Proliferation, Migration, and Invasion by Acting as a Competing Endogenous RNA of miR-19a. Oncol Res 2017; 25: 1471-1478. https://doi.org/1 $0.3727 / 096504017 X 14886689179993$ 